\title{
A atuação do enfermeiro na prevenção do câncer de pênis
}

\author{
Aline Soares Castro*, Bruno de Oliveira*, Caroline da Silva França*, Ana Cristina da Silva Oliveira** \\ *Acadêmicos de Enfermagem, ${ }^{* *}$ Docente do Centro Universitário Plínio Leite
}

\begin{abstract}
Resumo
O câncer de pênis é um tumor raro, com maior incidência em indivíduos a partir dos 50 anos de idade, relacionado à má higienização, fimose e doenças como HPV (Human Papiloma Virus). Em 2009, no Brasil, a estimativa de indivíduos portadores de câncer de pênis era de 4.637, em 2007 foram registradas 295 mortes. A importância da atuação do enfermeiro na prevenção do câncer peniano é o objeto da nossa pesquisa. Objetivamos descrever as ações do enfermeiro na prevenção do câncer peniano e conhecer atividades educativas numa abordagem para a prevenção do câncer peniano, levando-nos a um questionamento: como o enfermeiro pode contribuir para a prevenção do câncer peniano? Sendo assim, fizemos uma pesquisa bibliográfica no banco de dados da BVS (Biblioteca virtual de Saúde), de caráter descritivo exploratório e de abordagem qualitativa. Pretendemos contribuir para a atuação do profissional de enfermagem na assistência à população masculina, de modo a conscientizá-la que o câncer peniano é prevenível e utilizar uma abordagem educativa orientando que atitudes simples como a limpeza correta do órgáo sexual pode evitar o surgimento desse tipo de neoplasia e suas complicaçóes podem ser reduzidas caso o paciente procure o atendimento especializado adequado.
\end{abstract}

Palavras-chave: prevenção primária, papel do profissional de enfermagem, neoplasias penianas.

\section{Abstract}

\section{The nurse's role in the prevention of penile cancer}

Penile cancer is a rare tumor, with high incidence among individuals aged over 50 years, associated with poor hygiene, phimosis and diseases such as HPV (Human Papilloma Virus). In 2009, in Brazil, was estimated that 4637 patients had penile cancer; in 2007 there were 295 deaths. The importance of nurse's role in the prevention of penile cancer is the aim of this study. We aimed to describe the nurse's action in the prevention of penile cancer and to know educational activities to prevent the disease, based on the following question: How can nurses contribute to penile cancer prevention? Thus, a literature review with descriptive and exploratory design with qualitative approach was carried out using the VHS (Virtual Health Library). We intend to contribute to nursing professional care in male population, making them aware that penile cancer is a preventable disease, that single actions such as to clean sexual organ properly can prevent the onset of cancer and that its complications can be reduced in case the patient seeks proper specialized care.

Key-words: primary prevention, nurse's role, penile neoplasms. 


\section{Resumen}

\section{El papel del enfermero en la prevención del cáncer de pene}

El cáncer de pene es un tumor poco frecuente, con mayor incidencia en personas de 50 años de edad y está estrechamente vinculado a la falta de higiene, fimosis y enfermedades como el VPH (Virus del Papiloma Humano). En 2009, en Brasil, las estimaciones de individuos con cáncer de pene fue 4637, en 2007 fueron registradas 295 muertes. La importancia del papel del enfermero en la prevención del cáncer de pene es el objeto de nuestra investigación. Nuestro objetivo es describir las acciones del enfermero en la prevención del cáncer de pene y conocer actividades educativas con un enfoque en la prevención de cáncer de pene, que nos lleva a una pregunta: ¿cómo los enfermeros pueden contribuir a la prevención del cáncer de pene? Así, se realizó una revisión de literatura en la base de datos de la BVS (Biblioteca Virtual en Salud), y se utilizó un enfoque cualitativo, tipo descriptivo exploratorio. Tenemos la intención de contribuir para la actuación de los cuidados del profesional de enfermería en la población masculina, con el fin de concientizarlos de que el cáncer de pene es prevenible y utilizar un enfoque educativo que orienta que acciones simples como limpiar el órgano sexual correctamente puede prevenir la aparición de ese tipo de neoplasia y sus complicaciones se pueden reducir si el usuario busca una atención especializada y adecuada.

Palabras-clave: prevención primaria, rol de la enfermera, neoplasias del pene.

\section{Introdução}

A educação em saúde é um fator relevante no âmbito da saúde masculina, principalmente na prevenção do câncer peniano.

O câncer de pênis é um tumor raro, com maior incidência em indivíduos a partir dos 50 anos de idade, muito embora tumores malignos do pênis possam ser encontrados em indivíduos jovens. Está relacionado a baixas condiçóes socioeconômicas e de instrução, à má higiene íntima e a indivíduos não circuncidados. No Brasil, o tumor representa $2 \%$ de todos os casos de câncer no homem, sendo mais frequente nas regióes Norte e Nordeste, do que nas regióes Sul e Sudeste. Nas regióes de maior incidência, o câncer de pênis supera os casos de câncer de próstata e de bexiga [1].

Em 2009, no Brasil, a estimativa de indivíduos portadores de câncer de pênis era de 4.637 e, no ano de 2007, foram registradas 295 mortes causadas pelos agravos da doença. Dados de mortalidade causados por esta neoplasia não foram divulgados para o ano de 2009 [1].

O carcinoma de células escamosas é a lesão maligna mais comum do pênis. Uma parcela dos pacientes com essa afecção procura os ambulatórios de urgências, os serviços de pequenos procedimentos cirúrgicos ou mesmo os ambulatórios de consulta eletiva em busca de tratamento ou orientaçôes, antes de se direcionar para serviços especializados. Como consequência, esses casos são triados de forma inadequada, com retardo no diagnóstico ou encaminhamento ao especialista, sem o diagnóstico histopatológico definitivo, com prejuízo para o paciente e consequente sobrecarga ao Sistema de Saúde [2].

"Deve-se orientar a população e os profissionais de saúde, com relação aos sintomas e à apresentação clínica da doença, para que o diagnóstico seja feito no seu estágio inicial, evitando um desgaste físico e emocional do paciente" [2]. A incidência da doença ainda é preocupante em países da América Latina, África e Ásia.

O carcinoma peniano é uma doença ainda pouco estudada, por ser rara em países desenvolvidos. Estudos mais recentes vêm permitindo a identificaçáo de novos fatores de risco para o câncer peniano, outrora desconhecidos, tais como a infecção persistente pelo HPV. O baixo perfil social, econômico e cultural dos pacientes gera retardo na procura de ajuda médica e uma consequente dificuldade para seguimento e tratamento. A morbidade do tratamento cirúrgico, além de distúrbios psicológicos, pode gerar incapacidade funcional em grande parte dos pacientes operados [3].

Tendo em vista esses dados epidemiológicos, como também a ausência de estudos científicos na área da enfermagem, este estudo se torna relevante para a nossa profissão. Nossa pesquisa tem como objeto a importância da atuação do enfermeiro na prevenção do câncer peniano. Muito embora os dados estatísticos apontem para um número não muito alto comparado a outros países, a prevenção sempre é o melhor caminho. 
$\mathrm{Na}$ formação acadêmica, todo profissional de enfermagem é educador, pensando nesse propósito, entramos em um questionamento que resultou em nosso problema de pesquisa: como o enfermeiro pode contribuir para a prevenção do câncer peniano? Objetivamos, então, descrever as açôes do enfermeiro na prevenção do câncer peniano e conhecer atividades educativas para sua prevenção.

A motivação para realizar o presente estudo ocorreu durante a discussão de casos clínicos na disciplina Enfermagem em Atenção Básica, na qual foi abordado o alto índice de casos da doença, que estaria levando a amputação parcial ou total do órgão em muitos homens. Também o fato de haver poucas pesquisas sobre o assunto gerou o interesse acadêmico para desenvolvimento desse tema de grande relevância para a saúde do homem. Esta pesquisa visa contribuir para o ensino superior, principalmente para o enfermeiro que atua diretamente na prevençáo e na promoçáo da saúde da comunidade e saúde da família, devido à escassez de artigos publicados sobre o assunto. Além disso, contribuir para a atuação do profissional enfermeiro na assistência à populaçáo masculina, de modo a conscientizá-la sobre a importância da prevençáo do câncer de pênis, no intuito de diminuir o número de casos no Brasil, uma vez que a saúde da mulher tem um foco mais abrangente, tanto na mídia, em estudos científicos, quanto em campanhas promovidas pelo Ministério da Saúde e outros órgáos ligados à saúde coletiva.

\section{Material e métodos}

No tipo de estudo descritivo exploratório, os fatos são observados, registrados, analisados, classificados e interpretados, sem interferência do pesquisador. São utilizadas técnicas padronizadas de coleta de dados (questionário e observaçáo sistemática). $\mathrm{O}$ interesse pode se descrever o fato ou fenômeno [4].

Tratou-se de uma pesquisa bibliográfica. $\mathrm{O}$ material para a consolidação da pesquisa bibliográfica já deve ter sido publicado e constitui-se principalmente de livros, artigo de periódicos e atualmente de material disponibilizado na internet [4].

As informaçóes obtidas não podem ser quantificáveis e os dados obtidos são analisados indutivamente. A interpretação dos fenômenos e a atribuição de significados são básicas no processo de pesquisa qualitativas [4].

O quadro I representa o quantitativo de artigos encontrados com os descritores usados individualmente no banco de dados da BVS, nas fontes do Lilacs, BDENF e Medline.

Quadro I - Sistematização de dados.

\begin{tabular}{|l|l|l|l|}
\hline \multicolumn{1}{|c|}{ Descritores } & \multicolumn{3}{c|}{ BVS } \\
\hline & \multicolumn{1}{|c|}{ Lilacs } & BDENF & Medline \\
\hline Prevenção primária & 15808 & 1099 & 671923 \\
\hline Neoplasias penianas & 18054 & 308 & 76683 \\
\hline $\begin{array}{l}\text { Papel do profissional de } \\
\text { enfermagem }\end{array}$ & 467970 & 15993 & 13016 \\
\hline
\end{tabular}

Após o registro de artigos encontrados, foi realizado o refinamento, associando assim os descritores em três duplas e um trio, mostrados no quadro II.

Quadro II - Associação dos descritores.

\begin{tabular}{|l|l|l|l|}
\hline \multicolumn{1}{|c|}{ Descritores } & \multicolumn{2}{c|}{ BVS - Banco de Dados } \\
\hline & Lilacs & BDENF & Medline \\
\hline $\begin{array}{l}\text { Prevenção primaria + neo- } \\
\text { plasias penianas }\end{array}$ & 126 & 45 & 0 \\
\hline $\begin{array}{l}\text { Papel do profissional de } \\
\text { enfermagem + prevenção } \\
\text { primária }\end{array}$ & 1055 & 125 & 0 \\
\hline $\begin{array}{l}\text { Papel do profissional de } \\
\text { enfermagem + neoplasias } \\
\text { penianas }\end{array}$ & 258 & 82 & 0 \\
\hline $\begin{array}{l}\text { Papel do profissional de } \\
\text { enfermagem + neoplasias } \\
\text { penianas + prevenção } \\
\text { primária }\end{array}$ & 1181 & 126 & 0 \\
\hline
\end{tabular}

Após a coleta de dados, foi realizada uma pré-leitura, que permitiu uma visão global do assunto a ser tratado, além de permitir selecionar documentos que apresentassem dados ou informaçóes importantes que poderiam ser aproveitadas na fundamentação teórica do trabalho. A pré-leitura ou leitura de reconhecimento pode ser feita, no caso de livros, através de um exame prévio da folha de rosto, dos índices, da bibliografia, do prefácio, da introdução e conclusão. Artigos científicos exigem uma leitura integral para que haja compreensão do assunto.

\section{Resultados e discussão}

Após refinamento foi realizada uma leitura seletiva e destacamos os artigos no quadro III. 
Quadro III - Amostra.

\begin{tabular}{|c|c|c|c|c|}
\hline Autor & Ano & Título & $\begin{array}{l}\text { Base de } \\
\text { dados }\end{array}$ & Revista \\
\hline $\begin{array}{l}\text { Bengió GR, Ariel GF, Ipohor- } \\
\text { ski LG, Villarreal C, Orella- } \\
\text { na S, Olmedo L, Kerkebe R. }\end{array}$ & 2003 & $\begin{array}{l}\text { Cáncer de pene: revisión de casuística } \\
\text { junio de } 1995 \text { a junio de } 2002\end{array}$ & Lilacs & $\begin{array}{l}\text { Rev Chil Urol } \\
2003 ; 68(2): 156-61\end{array}$ \\
\hline Cestari MEW, Zago MMF & 2005 & $\begin{array}{l}\text { A prevenção do câncer e a promoção } \\
\text { da saúde: um desafio para o século XXI }\end{array}$ & BDENF & $\begin{array}{l}\text { Rev Bras Enferm } \\
2005 ; 58(2): 218-21\end{array}$ \\
\hline Silva MLM, Caldas NP & 2005 & $\begin{array}{l}\text { Especialização em oncologia para o } \\
\text { técnico de enfermagem: um modelo } \\
\text { do Instituto Nacional de Câncer }\end{array}$ & BDENF & $\begin{array}{l}\text { Rev Enferm UERJ; } \\
13(2): 217-22\end{array}$ \\
\hline Ampié MJC & 2005 & $\begin{array}{l}\text { Comportamiento clínico epidemiológi- } \\
\text { co del cáncer de pene en pacientes de } \\
\text { servicios de urología del HEALF, HEO- } \\
\text { DRA Enero 1999- diciembre } 2004\end{array}$ & Lilacs & $\begin{array}{l}\text { Managua; s.n; oct. } 2005 . \\
82 \text { p. Tab. Graf. }\end{array}$ \\
\hline $\begin{array}{l}\text { Barros FD, Pompeu ACL, } \\
\text { Lorenzato FRB, Matos, FCM, } \\
\text { Arap S, Silva MEF }\end{array}$ & 2006 & $\begin{array}{l}\text { Linfadenectomia inguinal radical } \\
\text { versus modificada no tratamento do } \\
\text { câncer de pênis }\end{array}$ & Lilacs & $\begin{array}{l}\text { An Fac Med Univ Fed } \\
\text { Pernamb 2006;51 (2):123- } \\
30 .\end{array}$ \\
\hline $\begin{array}{l}\text { Guimarães GC, Costa } \\
\text { Junior WL, Coelho EIDG, } \\
\text { Fonseca FP, Zequi SC, Maia } \\
\text { MAC, Lopes A }\end{array}$ & 2006 & Câncer de Pênis & Lilacs & $\begin{array}{l}\text { Manual de condutas } \\
\text { diagnósticas e terapêuticas } \\
\text { em Oncologia. São Paulo: } \\
\text { Ambito; 2006. p.639-42. }\end{array}$ \\
\hline $\begin{array}{l}\text { Duque } M \text {, Rojas JC, Tobón } \\
\text { LM, Currea D, López LJ }\end{array}$ & 2007 & $\begin{array}{l}\text { Biopsia de gangliolinfático centinela } \\
\text { en cáncer de pene con enfermedad } \\
\text { clínicamente negativa }\end{array}$ & Lilacs & $\begin{array}{l}\text { Urol Colomb } \\
2007 ; 16(3): 101-6 .\end{array}$ \\
\hline $\begin{array}{l}\text { Vieira SC, Feitosa Neto R, } \\
\text { Mattos PAL }\end{array}$ & 2007 & $\begin{array}{l}\text { Câncer de pênis: estudo retrospectivo } \\
\text { de } 99 \text { casos }\end{array}$ & Lilacs & $\begin{array}{l}\text { J Bras Med 2007; } \\
\text { 93(4):54. }\end{array}$ \\
\hline $\begin{array}{l}\text { Neveu C R, Bórquez MP, Tru- } \\
\text { jillo L, Cristián FR, Fernán- } \\
\text { dez R, Roberto BFM }\end{array}$ & 2008 & $\begin{array}{l}\text { Experiencia de } 10 \text { años en el manejo } \\
\text { del cáncer de pene. Instituto Nacional } \\
\text { del Cáncer (1997 - 2006) }\end{array}$ & Lilacs & $\begin{array}{l}\text { Rev Chil Cir 2008; } \\
60(2): 103-7\end{array}$ \\
\hline $\begin{array}{l}\text { Gonçalves AP, Faria RRM, } \\
\text { Prado C }\end{array}$ & 2009 & $\begin{array}{l}\text { O profissional de enfermagem no cui- } \\
\text { dado da dor de pacientes oncológicos }\end{array}$ & BDENF & $\begin{array}{l}\text { Nursing (São Paulo) } \\
\text { 2009;12(133):275- } 79 .\end{array}$ \\
\hline
\end{tabular}

O câncer do pênis é uma das mais antigas neoplasias conhecidas, apresenta distribuição geográfica desigual entre os diferentes países e grupos raciais. No Brasil, sua frequência é variável dependendo da região considerada, tendo mais frequência na região norte e nordeste. O seu curso, física e psicologicamente mutilante, e os decepcionantes resultados terapêuticos o situam entre os mais perigosos tumores humanos [5].

Os exames preventivos, por mais que ocorram no início da enfermidade, são capazes de detectá-lo, mas não de impedir o seu surgimento. No homem, o câncer de pênis é uma exceção a esta regra. Especialistas atestam que o tipo pode ser evitado, caso os que possuem predisposição a tê-lo sigam orientaçóes simples sobre como fazer a limpeza correta do órgão sexual. Essa vantagem, no entanto, não tem sido bem aproveitada e a realidade se encarrega de mostrar que o câncer peniano continua a existir, fazendo vítimas, principalmente, nas regiōes mais pobres, onde a desinformaçáo se torna o principal obstáculo no momento de combatê-lo [6].

Os principais fatores de risco para o câncer peniano são papiloma vírus humano (HPV) principalmente em lesóes com padrão basalóide ou verrucoso, fimose, condiçóes inflamatórias crônicas (por exemplo, balanopostites e líquen escleroso e atrófico), fotoquimioterapia com UVA (raios ultravioleta $\mathrm{A}$ ou PUVA = raios ultravioleta $\mathrm{A} \mathrm{e}$ psoralênico) e tabagismo [7].

As feridas malignas podem ser confundidas com outras úlceras venéreas provocadas por doenças como sífilis, por exemplo. Por isso, é importante que o médico observe, se a ferida não sumir depois do tratamento para sífilis, ele tem de pensar em câncer de pênis [8].

As formas de apresentação variam desde área endurada ou eritematosa, representada por pequeno 
nódulo, ou crescimento verrucoso, até lesão exofítica mais exuberante. Pode-se manifestar também, como ferida superficial que não cicatriza ou úlcera profunda com bordas elevadas. Na anamnese da dor, a intensidade referida pelo paciente nem sempre é proporcional ao acometimento local [2].

O diagnóstico dá-se através de biópsia incisional da lesão e o tratamento é realizado por meio de aplicação tópica de creme fluorouracil, radiação externa ou laser, através da amputação parcial ou total do órgão [7]. Segundo Faria o prognóstico do carcinoma epidermóide de pênis depende do estágio e do grau de diferenciaçáo celular e o grau maior se relaciona a uma incidência maior de metástases. A sobrevida de cinco anos de pacientes sem metástases ganglionares é de $80 \%$ e com metástases é de $50 \%$ [9]

A amputação do pênis traz graves consequências, alguns pacientes acabam cometendo suicídio, os que se mantêm vivos correm o risco de o câncer disseminar para os linfonodos da regiáo inguinal e morrer em três meses. Os médicos explicam que a alternativa é a reconstrução peniana, com tecido de outras partes do corpo. Mas o efeito é apenas estético, não há sensibilidade, e essa cirurgia só pode ser feita se, após cinco anos da retirada do órgão, não houver recidiva [8].

\section{Fatores de risco identificados pelo enfermeiro para prevençáo do câncer peniano}

"Homens que não foram operados de fimose possuem maior probabilidade de desenvolver este tipo de câncer. A fimose ocorre quando a pele de prepúcio é muito estreita ou pouco elástica, o que impede a exposiçáo da glande, dificultando, assim, uma limpeza adequada" [9].

"O crescimento exagerado do prepúcio aumenta os riscos de câncer de pele, já que dificulta a limpeza da região. Por outro lado, a circuncisão reduz a $1 / 3$ a incidência da doença”" [7].

Com a não circuncisão, há um acúmulo de esmegma, que é uma secreção produzida pelo organismo e, segundo os médicos, fica acumulada próximo à glande provocando pequenas feridas que evoluem para o câncer.

Outro fator de risco é a prática sexual com diferentes parceiros sem o uso de preservativo. A utilização do preservativo é imprescindível em qualquer relação sexual, pois ela diminui a chance de contágio de doenças sexualmente transmissíveis, como o vírus HPV, por exemplo. Alguns estudos científicos sugerem a associação entre infecção pelo HPV e câncer de pênis.

\section{Atuaçáo do enfermeiro nas açóes educativas em saúde visando à prevençáo}

Ao longo da graduação, aprendemos que o enfermeiro tem que prestar um cuidado humanizado e individualizado, respeitando as peculiaridades de cada cliente, mas na saúde coletiva cuida do indivíduo como um todo. Aprendemos, também, que o enfermeiro além de cuidado é um educador, e partindo desse princípio, vimos que enquanto educador, o profissional de saúde deve implementar em sua comunidade métodos para levar conhecimento à população, pois a prevenção sempre é o melhor caminho a seguir.

Sendo as condiçôes relacionadas ao câncer de pênis, em ordem de importância, os hábitos de higiene genital; o comportamento sexual de risco, causador do HPV; e a circuncisão, conclui-se que este é um tipo de câncer fácil de prevenir, dependendo principalmente de investimentos em educação. Esta deveria ser uma medida localizada por regiôes e focada nos hábitos de higiene e de comportamento sexual, atendendo a várias doenças e não apenas ao câncer de pênis [10].

Precisamos também mudar paradigmas, preconizando a superação do modelo de mulher e saúde para o de gênero e saúde. A proposta de programas de saúde voltados para gênero busca sair de um enfoque do risco e do dano da saúde da mulher para o da saúde como satisfação das necessidades humana.

Acreditamos que são igualmente válidos os posicionamentos que enfocam a saúde da mulher $\mathrm{e}$ a saúde do homem, desde que tais posicionamentos não percam a perspectiva relacional entre os gêneros e não se distanciem da promoção da saúde voltada para as necessidades humanas em geral. Pensar sobre a relação não significa desconsiderar demandas específicas de cada gênero [11].

A saúde do homem não é focada da mesma forma que da mulher, a falta de informaçáo sobre exames de rotina e a educação continuada, prejudicam um possível diagnóstico precoce de doenças relacionadas à saúde masculina.

Devido aos fatores de risco e prognóstico da doença devemos focar na educaçáo continuada para que haja prevençáo da mesma através de um diag- 
nóstico precoce e orientação aos pacientes quanto às causas que podem levar ao câncer peniano, evitando lesóes físicas e emocionais ao paciente.

O esmegma, que se forma em torno da glande, precisa ser removido diariamente, pois ele é irritativo tanto para o homem quanto para a sua parceira sexual, sendo de fácil remoção, com água e sabão durante o banho.

$\mathrm{O}$ avanço na prevenção e tratamento do HPV também deve resultar em redução na incidência do câncer. É constatada a presença de HPV, em cerca de $50 \%$ dos homens que desenvolveram câncer de pênis. Ainda que isso não estabeleça uma relação direta de causa entre o HPV e o câncer, a redução do índice de HPV certamente tem algum impacto sobre a incidência de câncer de pênis. O HPV atinge cerca de $30 \%$ da populaçáo. Nas mulheres que desenvolvem câncer de colo de útero, cerca de 100\% também acusa presença de HPV.

\section{Conclusão}

Concluímos que com medidas simples de prevenção como a higiene íntima masculina, educação em saúde, quebra de paradigmas de gênero entre os profissionais de saúde, é possível combater o câncer de pênis e evitar que o mesmo se agrave causando transtornos que em alguns casos são irreversíveis, exemplo das amputaçôes. Ainda assim é necessário que os profissionais de saúde se unam na melhora do diagnóstico que ainda é impreciso. Os doentes procuram as unidades de emergência quando a doença está muito avançada e o diagnóstico é feito de forma inadequada muitas vezes não confirmando o resultado de neoplasia, pela semelhança com outras doenças sexualmente transmissíveis, impedindo o tratamento adequado.

Enquanto educador, o enfermeiro pode promover diversas atividades em diversificadas áreas de atuação, promovendo a saúde e prevenindo doenças. O profissional deve buscar também parcerias junto à comunidade, realizando ações sociais, disseminando conhecimento para a população, no intuito de criar novos hábitos de prevenção, assim gerando estratégias para atingir o público masculino.

\section{Referências}

1. Instituto Nacional do Câncer. Câncer de pênis. [citado 2009 Abril 15]. Disponível em: URL: http//www. inca.gov.br.

2. Nunes DS, Magalhães FJS, Castro MV, Brólio $\mathrm{CH}$, Amaral VF, Barbosa IA, Silva AL. Diagnóstico clínico e histopatológico do câncer de pênis: A importância da biópsia pelo cirurgião geral. Rev Med Minas Gerais 2003; 13(4):248-50

3. Paula AAP, Netto JCA, Cruz AD, Júnior RF. Carcinoma epidermóide do pênis: consideraçóes epidemiológicas, histopatológicas, influência viral e tratamento cirúrgico. Rev Bras Cancer 2005;51(3):243-52.

4. Rodrigues WC. Metodologia científica. [citado 2009 Mar 16]. Disponível em: URL: http//www.ebras.bio.br

5. Júnior $\mathrm{AAB}$, Athanázio PRF, Oliveira B. Câncer do pênis: estudo da sua patologia geográfica no Estado da Bahia, Brasil. Rev Saúde Pública 1984;18(6):429-35.

6. Barbosa T. Falta de higiene: principal causa do câncer de pênis. Folha de Pernambuco, 11 de junho de 2006.

7. Carvalho NS, Kannenberg AP, Munaretto C, Yoshioka D, Absy MCV, Ferreira MA, et al. Associação entre HPV e câncer peniano: revisão da literatura. J Bras Doenças Sex Transm 2007;19(2):92-5.

8. Clébicar T. Sociedade Brasileira lança campanha contra câncer de pênis. O Globo online. [citado 2009 Jul 1]. Disponível em URL: http//www.oglobo.globo.com/ saude/vivermelhor

9. Faria SM, Martins ACP, Velludo MASL, Suaid HJ, Tucci S, Cologna AJ. Imunoexpressão do Ki-67 no carcinoma do pênis. Acta Cir Bras 2000;15(2):31-33.

10. Inca. Câncer de pênis. [citado 2009 Jun 1]. Disponível em URL: http//www.inca.gov.br

11. Gomes R. Sexualidade masculina e saúde do homem: proposta para uma discussão. Ciênc Saúde Coletiva 2003;8(3):825-9. 